\title{
The Sorption of Ni(II) by Grape Shell Ash from Aqueous Solution: Kinetic and Thermodynamic Studies
}

\author{
Nahid Ghasemi, Maryam Ghasemi, and Yaghoub Khosravi-Fard \\ Department of Chemistry, Sciences Faculty, Islamic Azad University, Arak Branch, P.O. Box 38135-567, Arak, Iran \\ Correspondence should be addressed to Nahid Ghasemi; n-ghasemi@iau-arak.ac.ir
}

Received 20 July 2013; Accepted 24 August 2013

Academic Editors: W. Cantwell and J. M. Deitzel

Copyright (C) 2013 Nahid Ghasemi et al. This is an open access article distributed under the Creative Commons Attribution License, which permits unrestricted use, distribution, and reproduction in any medium, provided the original work is properly cited.

\begin{abstract}
The sorption of $\mathrm{Ni}(\mathrm{II})$ onto grape shell ash (GSA) was studied by performing batch kinetic sorption experiments. The influences of major parameters in Nickel(II) ions sorption on GS such as initial of $\mathrm{pH}$, initial concentration of $\mathrm{Ni}(\mathrm{II})$ ions, the initial temperatures of solution, and contact time were investigated. The maximum increase in the rate of sorption of Ni(II) ions on GS was observed at an initial $\mathrm{pH}=5$, initial concentration of nickel $50 \mathrm{mgL}^{-1}$, temperature of solution $(328 \mathrm{~K})$, and $t=90 \mathrm{~min}$. The rate constants and the equilibrium sorption capacities were calculated. The results indicate that the sorption process follows the second-order kinetics and the values of rate constants were found to be $0.224,0.402,0.193$ and $0.123 \mathrm{~min}^{-1}$ at $298,308,318$, and $328 \mathrm{~K}$, respectively. The values of correlation coefficients for the adsorption of Ni(II) on GSA from all the systems were found to be 0.999 , and the values of predicted equilibrium sorption capacities showed good agreement with the experimental equilibrium uptake values. The thermodynamic parameters $\left(\Delta G^{\circ}, \Delta H^{\circ}\right.$, and $\left.\Delta S^{\circ}\right)$ of the adsorption process were calculated, and these parameters showed that the adsorption process is spontaneous.
\end{abstract}

\section{Introduction}

The presence of heavy metals in the environment is of major concern because of their toxic nature and tendency for bioaccumulation in the food chain even in relatively low concentrations [1-5]. The discharge of water containing heavy metals causes critical pollution problems. Nickel (II) ion is one such heavy metal frequently encountered in wastewater streams from industries such as electroplating, battery manufacture, mineral processing, steam-electric power plants, paint formulation, and porcelain enameling [6-8]. In drinking water and for industrial wastewater, the tolerance limit of nickel is $0.01 \mathrm{mg} \mathrm{L}^{-1}$ and $2.0 \mathrm{mg} \mathrm{L}^{-1}$. Cancer of nose, bone, and lungs is created. Dermatitis (nickel itch) is the most frequent effect of exposure to nickel, such as coins and costume jewelry. Nickel carbonyl $\left[\mathrm{Ni}(\mathrm{CO})_{4}\right]$ has been estimated as lethal in humans at atmospheric exposures of $30 \mathrm{mg} \mathrm{L}^{-1}$ for $30 \mathrm{~min}$ [3]. Acute $\mathrm{Ni}(\mathrm{II})$ poisoning causes dizziness, headache, nausea and vomiting, chest pain, dry cough and shortness of breath, rapid respiration, cyanosis, and extreme weakness [9-12]. These harmful effects of $\mathrm{Ni}(\mathrm{II})$ necessitate its removal from wastewaters before the release into streams. Several treatment methods such as membrane filtration, chemical precipitation, chemical oxidation/reduction, ion exchange, filtration, electrochemical treatment, solvent extraction, co-precipitation, and adsorption have been reported for the removal of metallic ions from water and wastewater [13]. Adsorptive removal is based on the ability of a porous adsorbent to selectively adsorb some specific compounds from the atmosphere or refinery streams. The compounds, which have a suitable size and shape, can be removed via adsorption. Based on the types of interactions between an adsorbate and a porous sorbent, the adsorption can be categorized as a physical or chemical one [14]. Various porous adsorbents such as activated carbons, zeolites, and mesoporous materials have been investigated for adsorptive removal of hazardous compounds.

A grape is a fruiting berry of the deciduous woody vines of the botanical genus Vitis. Grapes can be eaten raw or they can be used for making jam, juice, jelly, grape seed extract, raisins, vinegar, and grape seed oil. Italy ranks first in grape production in the world and Iran ranks eleventh in grape production, a potential of 3 million tons of grape are produced annually. The total area planted of grape is 310.000 hectare. This shows a high potential of grape shells produced 
during pruning step each year that have little value. This leads to a need to convert this by-product to useful, value added product, such as adsorbent. To our knowledge, no investigations have used grape shells as precursor to produce adsorbent and ash.

In this study, we attempt to utilize grape shell waste, an agricultural waste available in Iran as a sorbent to remove $\mathrm{Ni}$ ions from aqueous solution. This study mainly focuses on the effect of some environmental parameters such as solution $\mathrm{pH}$, initial $\mathrm{Ni}$ (II) concentration, contact time, and temperature on the ability of Grape Shell ash (GSA) to biosorb Ni(II) ions from aqueous solutions and to determine the mechanism that govern $\mathrm{Ni}$ (II) ions removal as well as to find a suitable kinetic model for the adsorption process.

\section{Experimental}

2.1. Preparation of the Adsorbent. GS was obtained from one of the villages of Arak in Iran. Unmodified sorbent was washed several times with warm distilled water to remove impurities and was dried at $105^{\circ} \mathrm{C}$ for $24 \mathrm{~h}$ and cut into small pieces of sizes between 2.0 and $5.0 \mathrm{~mm}$. The material was placed in a vertical stainless steel reactor and heated in a furnace at a rate of $10^{\circ} \mathrm{C} \mathrm{min}^{-1}$ from room temperature to $450^{\circ} \mathrm{C}$. The black residue was cooled and sieved to get GS ash (GSA) with an average particle size of $0.125 \mathrm{~mm}$ and finally stored in air glass container.

2.2. Reagents. Solution of metal ions (nickel nitrate) was of analytical grade. Synthetic stock solution $\left(1000 \mathrm{mg} \mathrm{L}^{-1}\right)$ of $\mathrm{Ni}$ (II) ions was prepared by dissolving the required quantity of $\mathrm{Ni}\left(\mathrm{NO}_{3}\right)_{2} \cdot 6 \mathrm{H}_{2} \mathrm{O}$ in double distilled water. Working solutions of the desired concentration were then prepared by successive dilution. All the solutions were made using deionized distilled water. $\mathrm{pH}$ adjustments were performed with $\mathrm{HNO}_{3}$ and $\mathrm{NaOH}$ (Merck) solutions $0.1 \mathrm{~N}$. All chemicals used in the experiments were reagent analytical grade.

2.3. Apparatus. The $\mathrm{Ni}$ ion concentration in the solutions was determined by Atomic Absorption Spectrometer (model AA 680 made of SHIMADZU) using a standard calibration curve. The $\mathrm{pH}$ was measured via the Swiss-made Metrohm $827 \mathrm{pH}$ meter with a combined glass electrode.

2.4. Batch Adsorption Experiments. Batch experiments were conducted in order to study the effect of important parameters like the $\mathrm{pH}$, contact time, and the initial ion concentration on the adsorptive removal of Ni ion using GSA. For the batch adsorption experiments, $50 \mathrm{~mL}$ solution of $\mathrm{Ni}$ (II) of initial concentration $10 \mathrm{mg} \mathrm{L}^{-1}$ was contacted with $50 \mathrm{mg}$ GSA. The contents were placed in a stirrer and gently agitated at $150 \mathrm{rpm}$. The solution was filtered, and the residual $\mathrm{Ni}$ concentration was analyzed. The effect of the initial $\mathrm{pH}$ onto the GSA was studied across a $\mathrm{pH}$ range of 2.0-5.0 in different time with a fixed adsorbent concentration. The effect of the initial concentration and contact time on the uptake of the $\mathrm{Ni}$ ions was conducted by varying the ion concentration from 5.0 to $50.0 \mathrm{mg} \mathrm{L}^{-1}$ at different contact times (0.0-90.0 min).

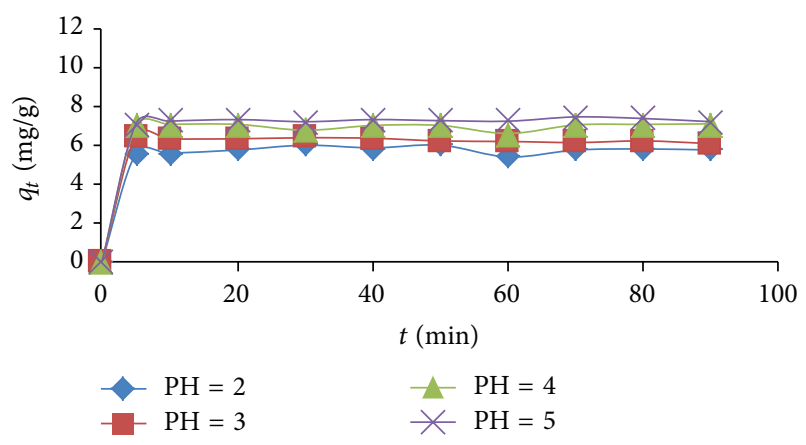

FIgURE 1: The influence of solution $\mathrm{pH}$ and agitation time on the removal of $\mathrm{Ni}(\mathrm{II})$ by GSA (Ni(II) concentration, $10 \mathrm{mg} \mathrm{L}^{-1}$, GSA dose, $1 \mathrm{~g} \mathrm{~L}^{-1}$; Agitation time, $\left.90 \mathrm{~min}\right)$.

TABLE 1: The maximum amount of $\mathrm{Ni}(\mathrm{II})$ sorbate as a function of $\mathrm{pH}$ at $20 \mathrm{~min}$.

\begin{tabular}{lc}
\hline $\mathrm{pH}$ & The maximum uptake efficiency $\left(\mathrm{mg} \mathrm{g}^{-1}\right)$ \\
\hline 2 & 7.2068 \\
3 & 7.6206 \\
4 & 8.8964 \\
5 & 9.0344 \\
\hline
\end{tabular}

The percent of $\mathrm{Ni}(\mathrm{II})$ removal $(\% R)$ and the amount of adsorbed $\mathrm{Ni}(\mathrm{II})$ at equilibrium, $q_{e}$, were calculated as follows:

$$
\begin{gathered}
R \%=\left[\frac{C_{i}-C_{e}}{C_{i}}\right] \times 100, \\
q_{e}=\frac{C_{i}-C_{e}}{m} V,
\end{gathered}
$$

where $C_{e}$ and $C_{i}$ are the equilibrium and initial concentrations of $\mathrm{Ni}(\mathrm{II})\left(\mathrm{mg} \mathrm{L}^{-1}\right)$, respectively; $q_{e}$ is equilibrium $\mathrm{Ni}(\mathrm{II})$ concentration on adsorbent $\left(\mathrm{mg} \mathrm{g}^{-1}\right) ; V$ is the volume of $\mathrm{Ni}$ (II) solution (L); and $m$ is the mass of GSA sample used (g).

\section{Results and Discussion}

3.1. Effects of Solution $p H$ and Agitation Time. One of the main parameters affecting the metal adsorption from aqueous solution is the $\mathrm{pH}$ of the solution. The influence of solution $\mathrm{pH}$ and agitation time on the removal of $\mathrm{Ni}$ (II) by GSA was represented in Figure 1 and Table 1, for a period of 90 min. With increasing $\mathrm{pH}$ from 2 to 5 , adsorption capacity of adsorbent increased from 7.2 to $9.03 \mathrm{mg} \mathrm{g}^{-1}$.

In lower $\mathrm{pH}$, a higher concentration of $\mathrm{H}^{+}$ions present in the mixture competes with $\mathrm{Ni}$ (II) ions for the adsorption sites resulting in the reduced uptake of $\mathrm{Ni}(\mathrm{II})$. On the contrary, as the $\mathrm{pH}$ increases, the adsorbent surface becomes more and more negatively charged, and the adsorption of $\mathrm{Ni}(\mathrm{II})$ ions is more favorable. Figure 1 shows that the $\mathrm{Ni}$ (II) removal by GSA increases with increase in $\mathrm{pH}$ and the maximum of removal attains at 20 minutes. 


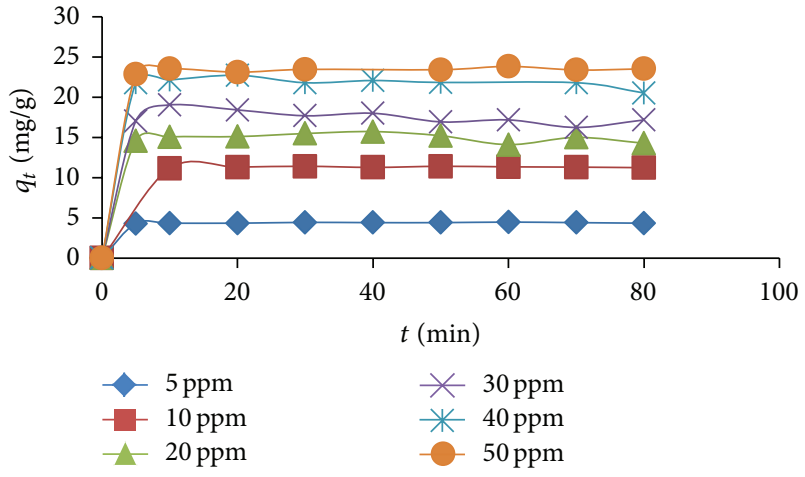

FIgUre 2: The influence of initial concentration and agitation time on the removal of $\mathrm{Ni}(\mathrm{II})$ by GSA $\left(\mathrm{pH}=5,10 \mathrm{mg} \mathrm{L}^{-1}\right.$; GSA dose, $1 \mathrm{~g} \mathrm{~L}^{-1}$; Agitation time, $90 \mathrm{~min}$ ).

TABLE 2: The maximum amount of $\mathrm{Ni}(\mathrm{II})$ sorbate as a function of initial concentration of $\mathrm{Ni}(\mathrm{II})$ at 40 minutes.

\begin{tabular}{lc}
\hline $\begin{array}{l}\text { Initial concentration } \\
\text { of } \mathrm{Ni}(\mathrm{II})\left(\mathrm{mg} \mathrm{L}^{-1}\right)\end{array}$ & $\begin{array}{c}\text { The maximum } \\
\text { uptake efficiency }\left(\mathrm{mg} \mathrm{g}^{-1}\right)\end{array}$ \\
\hline 5 & 4.3447 \\
10 & 11.2413 \\
20 & 14.2757 \\
30 & 17.1723 \\
40 & 20.5171 \\
50 & 23.5172 \\
\hline
\end{tabular}

3.2. Effect of Initial Concentration and Agitation Time. Figure 2 and Table 2 represent the removal of $\mathrm{Ni}(\mathrm{II})$ as a function of initial concentrations ranging from $5-50 \mathrm{mg} \mathrm{L}^{-1}$ by GSA. The uptake efficiency is increased from 4.344 to $23.517 \mathrm{mg} \mathrm{g}^{-1}$ with the increasing in initial $\mathrm{Ni}(\mathrm{II})$ concentration. This increase may be due to the ratio of the initial number of moles of $\mathrm{Ni}(\mathrm{II})$ to the available adsorption sites in adsorbent that is high at higher initial concentrations. Thus, at the same time, the time required for attaining the equilibrium state is highly independent on initial $\mathrm{Ni}(\mathrm{II})$ concentration. In Figure 2, the influence of contact time on the adsorption of $\mathrm{Ni}(\mathrm{II})$ on GSA is observed. According to Figure 2, the amount of $\mathrm{Ni}$ (II) adsorption onto GSA increases sharply up to the first 10 minutes and finally attain equilibrium where there is no further increase in the amount of adsorption. The uptake of adsorption of other adsorbents for the removal of $\mathrm{Ni}(\mathrm{II})$ from aqueous phase is given in Table 3 for comparison [15-18].

3.3. Adsorption Kinetic Study. Determination of uptake kinetics is important for the evaluation of a candidate adsorbent material. In order to estimate the uptake capacity of the sample in this study, three sorption kinetic models developed, pseudo-first-order, pseudo-second-order and Elovich equations by Lagergren [19], Ho and McKay [20], and Fatehi et al. [21], respectively, were used.

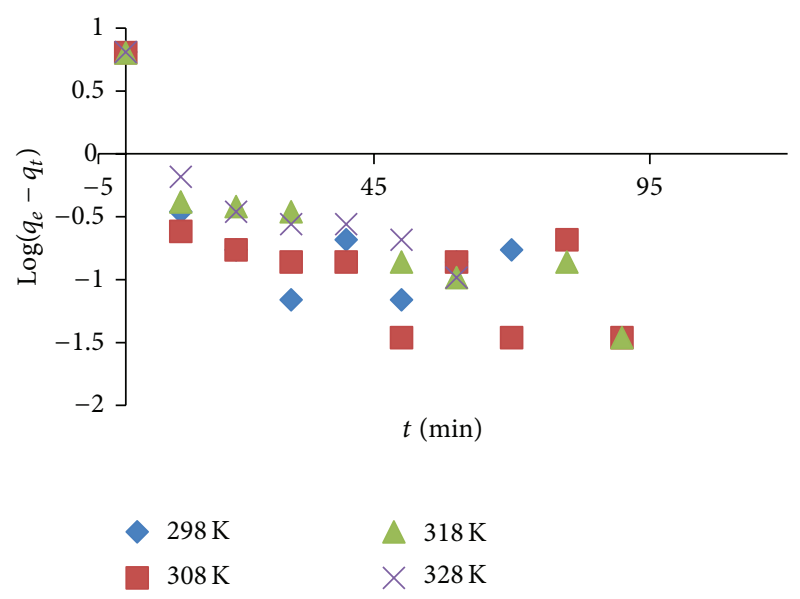

FIgURE 3: The pseudo-first-order plots for the adsorption of $\mathrm{Ni}(\mathrm{II})$ by GSA. (Ni(II) concentration, $10 \mathrm{mgL}^{-1}$, GSA dose, $1 \mathrm{gL}^{-1} ; \mathrm{pH}=6$ ).

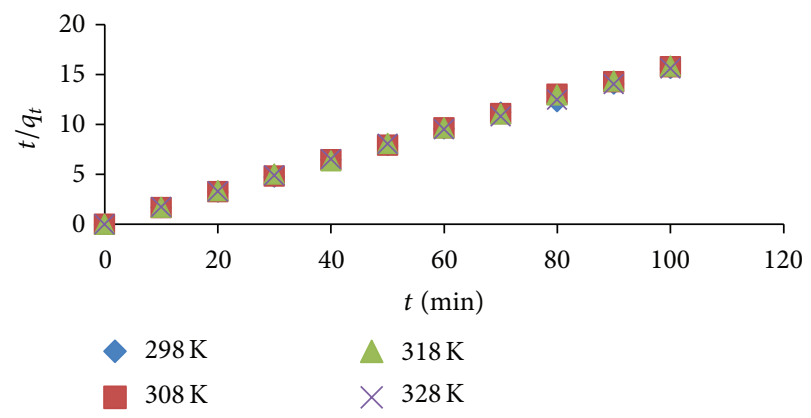

FIGURE 4: The pseudo second order plots for the adsorption of $\mathrm{Ni}(\mathrm{II})$ by GSA. (Ni(II) concentration, $10 \mathrm{mgL}^{-1}$, GSA dose, $1 \mathrm{gL}^{-1} ; \mathrm{pH}=6$ ).

The first and second order rate expressions given by (3) and (4) are respectively,

$$
\begin{gathered}
\log \left(q_{e}-q_{t}\right)=\log q_{e}-\frac{k_{1}}{2.303} t, \\
\frac{t}{q_{t}}=\frac{1}{k_{2} q_{e}^{2}}+\frac{t}{q_{e}}
\end{gathered}
$$

where $q_{e}$ and $q_{t}$ are the amounts of $\mathrm{Ni}(\mathrm{II})$ adsorbed $\left(\mathrm{mg} \mathrm{g}^{-1}\right)$ at equilibrium time and at time $t(\mathrm{~min})$ and $k_{1}$ and $k_{2}$ is the rate constants of adsorption.

The simplified form of Elovich's equation is shown in (5) is

$$
q_{t}=\frac{1}{b} \ln (a \cdot b)+\frac{1}{b} \ln (t),
$$

where $a$ is the initial adsorption rate $\left(\mathrm{mg} \mathrm{g}^{-1} \mathrm{~min}^{-1}\right)$, and the parameter $1 / b\left(\mathrm{mg} \mathrm{g}^{-1}\right)$ is related to the available sites for adsorption.

Initially, the validity of the two models was checked by studying the kinetics under different initial temperatures of solution. Linear plots of $\log \left(q_{e}-q_{t}\right)$ and $t / q_{t}$ versus $t$ showed the applicability of the above equations (the first and second order) for GSA (Figures 3 and 4 ). The $k_{1}$ and $k_{2}$ 
TABLE 3: Comparison of adsorption capacity of various adsorbents for the removal of $\mathrm{Ni}(\mathrm{II})$ from aqueous phase.

\begin{tabular}{lccc}
\hline Adsorbent & Range of $C_{o}\left(\mathrm{mg} \mathrm{L}^{-1}\right)$ & $Q_{o}\left(\mathrm{mg} \mathrm{g}^{-1}\right)$ & References \\
\hline Rice husk based & $50-200$ & 5.52 & {$[15]$} \\
Paddy straw based & $50-200$ & 11.50 & {$[16]$} \\
Sugarcane bagasse pith & $50-1000$ & 31.00 & {$[17]$} \\
Lotus stalks & $20-40$ & 23.517 & {$[18]$} \\
Grape shell ash & $5-50$ & & This study \\
\hline
\end{tabular}

TABLE 4: The pseudo-first-order, pseudo-second-order, and Elovich's equation kinetic parameters for Ni(II) sorption onto GSA at different temperatures of solution.

\begin{tabular}{|c|c|c|c|c|c|c|}
\hline & $T(\mathrm{~K})$ & Equation & $R^{2}$ & $q_{e . \mathrm{cal}}$ & $k_{1}$ & $q_{e . \exp }$ \\
\hline \multirow{5}{*}{ Pseudo- first-order equation } & 298 & $y=-0.0163-0.0603$ & 0.406 & 0.870964 & 0.036848 & 6.4137 \\
\hline & 308 & $y=-0.0151 x-0.1427$ & 0.479 & 0.721107 & 0.034545 & 6.3447 \\
\hline & 318 & $y=-0.0175 x+0.1621$ & 0.745 & 1.452112 & 0.039151 & 6.3102 \\
\hline & 328 & $y=-0.0231 x+0.3185$ & 0.757 & 2.079697 & 0.052969 & 6.4137 \\
\hline & $T(\mathrm{~K})$ & Equation & $R^{2}$ & $q_{\text {e. cal }}$ & $k_{2}$ & $q_{e . \exp }$ \\
\hline \multirow{5}{*}{ Pseudo-second-order equation } & 298 & $y=0.1553 x+0.1074$ & 0.999 & 6.451613 & 0.224533 & 6.4137 \\
\hline & 308 & $y=0.1586 x+0.0623$ & 0.999 & 6.329114 & 0.402645 & 6.3447 \\
\hline & 318 & $y=0.1581 x+0.1297$ & 0.999 & 6.329114 & 0.193519 & 6.3102 \\
\hline & 328 & $y=0.1541 x+0.1957$ & 0.999 & 6.493506 & 0.121621 & 6.4137 \\
\hline & $T(\mathrm{~K})$ & Equation & $R^{2}$ & $a$ & $b$ & $q_{e . \exp }$ \\
\hline \multirow{4}{*}{ Elovich equation } & 298 & $y=0.1352 x+5.7911$ & 0.605 & $5.740 * 10^{17}$ & 7.407407 & 6.4137 \\
\hline & 308 & $y=0.0787 x+5.9307$ & 0.484 & $8.096 * 10^{31}$ & 12.82051 & 6.3447 \\
\hline & 318 & $y=0.1959 x+5.4117$ & 0.727 & $2.191 * 10^{11}$ & 5.128205 & 6.3102 \\
\hline & 328 & $y=0.2894 x+5.1307$ & 0.926 & $1.47 * 10^{7}$ & 3.460208 & 6.4137 \\
\hline
\end{tabular}

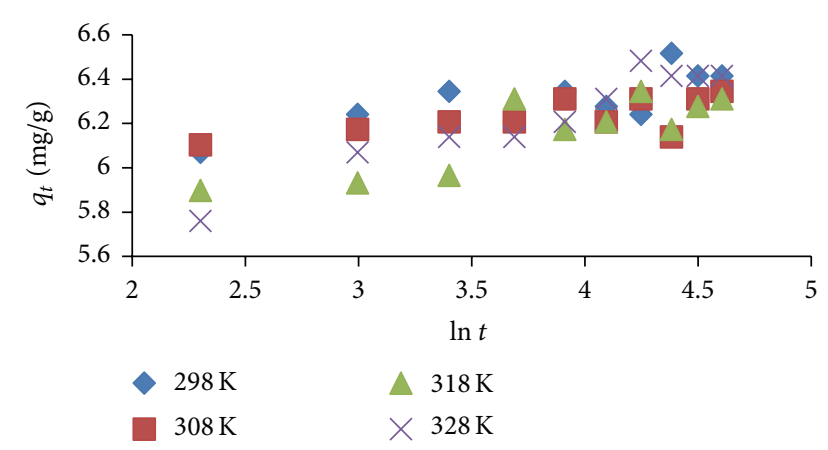

FIGURE 5: Elovich's equation plots for the adsorption of $\mathrm{Ni}(\mathrm{II})$ by GSA. (Ni(II) concentration, $10 \mathrm{mg} \mathrm{L}^{-1}$, GSA dose, $1 \mathrm{~g} \mathrm{~L}^{-1} ; \mathrm{pH}=6$ ).

values were calculated from the slopes of the linear plots and are presented in Table 4 . The Elovich constants ( $a$ and $b$ ) computed from the plots of $q_{t}$ versus $\ln t$ (Figure 5) are presented in Table 4. Correlation coefficients of the pseudofirst-order kinetic were found to be lower than 0.76 , and the calculated $q_{e}$ is not equal to experimental $q_{e}$, suggesting the insufficiency of pseudo-first-order model to fit the kinetic data for the initial concentrations examined. The reason for these differences in the $q_{e}$ values is that there is a time lag, possibly due to a boundary layer or external resistance controlling at the beginning of the sorption process [22]. In most cases of the literature, the pseudo-first-order model does not fit the kinetic data well for the whole range of contact time, and generally underestimate the $q_{e}$ values $[23,24]$. The pseudo-second order model is based on the sorption capacity of the solid phase. Contrary to other well established models, it predicts the behavior over the whole range of studies and it is in agreement with a chemisorption mechanism being the rate-controlling step [22].

The values of correlation coefficients for the adsorption of $\mathrm{Ni}$ (II) on GSA from all the systems were found to be 0.999 for pseudo-second-order kinetic model, and the values of predicted equilibrium sorption capacities showed good agreement with the experimental equilibrium uptake values. Based on correlation coefficients and $q_{e}$ values calculated, it is evident that the adsorption of $\mathrm{Ni}$ (II) can be best described by the pseudo-second-order kinetic model (Table 3 ).

Results of Table 3 also showed that the $k_{2}$ values decrease as temperature rises, confirming that the rate of biosorption is faster at lower temperatures, which is probably due to a decrease in the interactions between $\mathrm{Ni}$ (II) ions and GSA as the biosorbent. This behavior is a characteristic of exothermic reactions.

The $R^{2}$ values were in the range of 0.484 to 0.926 for the various temperatures ranging from $298 \mathrm{~K}$ to $328 \mathrm{~K}$ for Elovich's equation. The $q_{e}$ values calculated from the Elovich equation disagreed with the experimental $q_{e}$ values. It was observed that the Elovich model constants, namely, $a$ $\left(\mathrm{mg} \mathrm{g}^{-1} \mathrm{~min}^{-1}\right)$ and $b\left(\mathrm{mg} \mathrm{g}^{-1}\right)$, decreased with temperature. 
TABlE 5: The intraparticle diffusion kinetic parameters for Ni(II) sorption onto GSA at different temperatures of solution.

\begin{tabular}{|c|c|c|c|c|c|}
\hline$T(\mathrm{~K})$ & Equation & $R^{2}$ & $k_{i}$ & $I$ & $q_{e . \exp }$ \\
\hline 298 & $y=0.0437 x+5.9963$ & 0.590 & 0.043 & 5.996 & 6.4137 \\
\hline 308 & $y=0.0253 x+6.0509$ & 0.468 & 0.025 & 6.050 & 6.3447 \\
\hline 318 & $y=0.0628 x+5.7122$ & 0.699 & 0.062 & 5.712 & 6.3102 \\
\hline 328 & $y=0.0926 x+5.5765$ & 0.886 & 0.092 & 5.576 & 6.4137 \\
\hline
\end{tabular}

TABLE 6: Thermodynamic parameters for adsorption of Ni(II) onto GSA.

\begin{tabular}{lcccc}
\hline$T(\mathrm{~K})$ & $\ln k_{D}$ & $\Delta G\left(\mathrm{kJmol}^{-1}\right)$ & $\Delta H\left(\mathrm{kJmol}^{-1}\right)$ & $\Delta S\left(\mathrm{kJmol}{ }^{-1} \mathrm{~K}^{-1}\right)$ \\
\hline 298 & 3.4339 & -8.5078 & & -0.0276 \\
308 & 3.1357 & -8.0296 & -16.6762 & \\
318 & 3.0123 & -7.9642 & & \\
\hline
\end{tabular}

3.4. Adsorption Mechanism. To confirm whether Ni ions adsorption on GSA is dominated by intraparticle diffusion (Weber and Morris), the empirical data were analyzed using the intraparticle diffusion model [25]

$$
q_{t}=k_{i} t^{0.5}+I
$$

where $q_{t}\left(\mathrm{mgg}^{-1}\right)$ is the uptake of $\mathrm{Ni}$ ions at time $t, k_{i}$ $\left(\mathrm{mg} \mathrm{g}^{-1} \mathrm{~min}^{-1}\right)$ is the intraparticle diffusion rate constant, and $I\left(\mathrm{mg} \mathrm{g}^{-1}\right)$ indicates the thickness of the boundary layer, that is, larger values of $I$ suggest greater boundary layer effects. The calculated data for the adsorption of $\mathrm{Ni}$ (II) ions on to GSA at different temperature applied to diffusion model is shown in Figure 6, and the intraparticle diffusion constants are given in Table 5. No plots of model passed through the origin, showing that intraparticle diffusion was not sole ratecontrolling step although it was involved in the process. This emphasized that adsorption of $\mathrm{Ni}$ (II) ions was a two or more steps process [26].

3.5. Adsorption Thermodynamic Study. The thermodynamic parameters, Gibbs free energy $\left(\Delta G^{\circ}\right)$, enthalpy $\left(\Delta H^{\circ}\right)$, and entropy $\left(\Delta S^{\circ}\right)$ have an important role to determine spontaneity and heat change for the adsorption process. The thermodynamic parameters $\left(\Delta G^{\circ}, \Delta H^{\circ}\right.$ and $\left.\Delta S^{\circ}\right)$ were calculated using the following equations:

$$
\begin{gathered}
k_{D}=\frac{q_{e}}{C_{e}}, \\
\Delta G=-R T \ln k_{D}, \\
\ln k_{D}=\frac{\Delta S}{R}-\frac{\Delta H}{R T},
\end{gathered}
$$

where $k_{D}$ is the distribution coefficient of the adsorbate and $q_{e}$ and $C_{e}$ are as defined previously. $R$ is the universal gas constant $\left(8.314 \mathrm{~J} \mathrm{~mol}^{-1} \mathrm{~K}^{-1}\right)$ and $T$ is temperature $(\mathrm{K})$ [27]. $\Delta H^{\circ}$ and $\Delta S^{\circ}$ can be obtained from the slope and intercept of the plot $\ln k_{D}$ against $1 / T$, respectively (Figure 7). $\Delta G^{\circ}$ was obtained using (8) for different temperatures. The data in Table 6 showed that the standard free energy changes $\left(\Delta G^{\circ}\right)$ are negative $\left(-8.5078,-8.0296\right.$, and $-7.9642 \mathrm{~kJ} \mathrm{~mol}^{-1}$ at 298 , 308 , and $318 \mathrm{~K}$, resp.), indicating spontaneous adsorption of

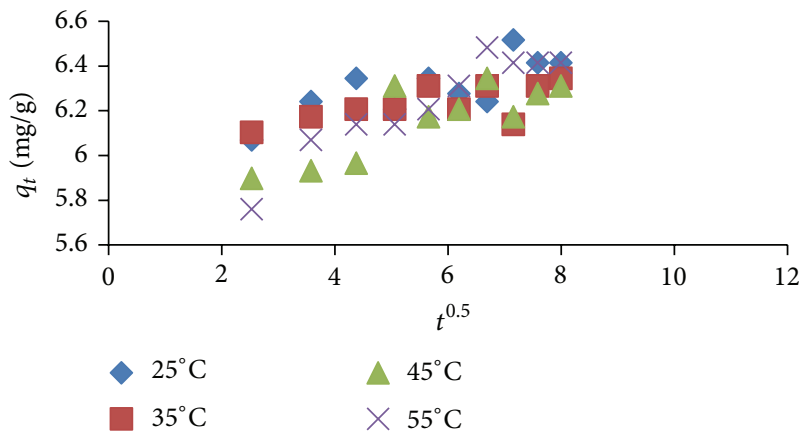

FIGURE 6: The intraparticle diffusion plots for the adsorption of $\mathrm{Ni}(\mathrm{II})$ by GSA. (Ni(II) concentration, $10 \mathrm{mg} \mathrm{L}^{-1}$, GSA dose, $1 \mathrm{gL}^{-1}$; $\mathrm{pH}=6)$.

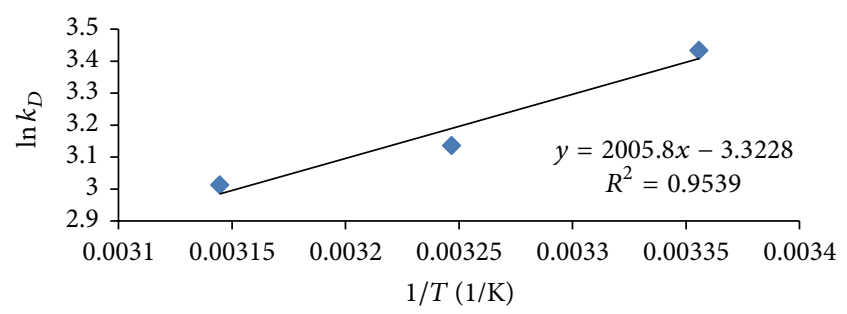

FIGURE 7: Plot of $\ln K_{D}$ against temperature $(1 / T)$ for the adsorption of $\mathrm{Ni}(\mathrm{II})$ by GSA.

$\mathrm{Ni}(\mathrm{II})$ ions on GSA for the temperature range studied (298, 308 and $318 \mathrm{~K})$. The negative $\Delta H^{\circ}$ value $\left(-16.6762 \mathrm{~kJ} \mathrm{~mol}^{-1}\right)$ showed the endothermic nature of the sorption process. Since diffusion is an exothermic process, it would be expected that increased solution temperature would result in decrease uptake of $\mathrm{Ni}(\mathrm{II})$ ions from aqueous solution. Also, the negative value of $\Delta S^{\circ}\left(-0.0276 \mathrm{~kJ} \mathrm{~mol}^{-1} \mathrm{~K}^{-1}\right)$ may be related to the decrease randomness.

\section{Conclusion}

The sorption characteristics of Grape Shell were studied for $\mathrm{Ni}(\mathrm{II})$. The results indicated that this adsorbent may be used as an inexpensive and effective material for the removal of 
$\mathrm{Ni}$ (II) from aqueous solutions but with a low efficiency. The sorption process was affected by experimental conditions such as $\mathrm{pH}$, initial concentration of $\mathrm{Ni}$ (II) ions, the initial temperatures of solution, and contact time. Analysis of the kinetic data showed that the kinetics of $\mathrm{Ni}$ (II) adsorption using Grape Shell ash as an adsorbent for different values of initial temperatures of solution is explained by the secondorder-kinetic model. The calculated thermodynamic parameters determined the spontaneous and endothermic nature of the $\mathrm{Ni}$ (II) biosorption process onto GSA.

\section{Acknowledgment}

The authors would like to thank the Islamic Azad University, Arak Branch, for providing the research fund for this project.

\section{References}

[1] A. Bhatnagar and A. K. Minocha, "Biosorption optimization of nickel removal from water using Punica granatum peel waste," Colloids and Surfaces B, vol. 76, no. 2, pp. 544-548, 2010.

[2] V. K. Gupta, R. Mangla, and S. Agarwal, " $\mathrm{Pb}(\mathrm{II})$ selective potentiometric sensor based on 4-tertbutylcalix[4]arene in PVC matrix," Electroanalysis, vol. 14, pp. 1127-1132, 2002.

[3] V. K. Gupta, P. J. M. Carrott, M. M. L. Ribeiro Carrott, and S. Suhas, "Low-cost adsorbents: growing approach to wastewater treatment-a review," Critical Reviews in Environmental Science and Technology, vol. 39, no. 10, pp. 783-842, 2009.

[4] V. K. Gupta, R. N. Goyal, and R. A. Sharma, "Novel PVC membrane based alizarin sensor and its application; determination of vanadium, zirconium and molybdenum," International Journal of Electrochemical Science, vol. 4, no. 1, pp. 156-172, 2009.

[5] A. K. Jain, V. K. Gupta, B. B. Sahoo, and L. P. Singh, "Copper(II)selective electrodes based on macrocyclic compounds," Analytical Proceedings including Analytical Communications, vol. 32, no. 3, pp. 99-101, 1995.

[6] V. K. Gupta, I. Ali, and V. K. Saini, "Defluoridation of wastewaters using waste carbon slurry," Water Research, vol. 41, no. 15, pp. 3307-3316, 2007.

[7] D. Nabarlatz, J. de Celis, P. Bonelli, and A. L. Cukierman, "Batch and dynamic sorption of $\mathrm{Ni}$ (II) ions by activated carbon based on a native lignocellulosic precursor," Journal of Environmental Management, vol. 97, no. 1, pp. 109-115, 2012.

[8] S. J. Kleinübing, E. Guibal, E. A. da Silva, and M. G. C. da Silva, "Copper and nickel competitive biosorption simulation from single and binary systems by Sargassum filipendula," Chemical Engineering Journal, vol. 184, pp. 16-22, 2012.

[9] A. Ewecharoen, P. Thiravetyan, and W. Nakbanpote, "Comparison of nickel adsorption from electroplating rinse water by coir pith and modified coir pith," Chemical Engineering Journal, vol. 137, no. 2, pp. 181-188, 2008.

[10] V. K. Gupta, A. Rastogi, and A. Nayak, "Adsorption studies on the removal of hexavalent chromium from aqueous solution using a low cost fertilizer industry waste material," Journal of Colloid and Interface Science, vol. 342, no. 1, pp. 135-141, 2010.

[11] V. K. Gupta, A. Rastogi, and A. Nayak, "Biosorption of nickel onto treated alga (Oedogonium hatei): application of isotherm and kinetic models," Journal of Colloid and Interface Science, vol. 342, no. 2, pp. 533-539, 2010.

[12] S. Yadav, V. Srivastava, S. Banerjee, F. Gode, and Y. C. Sharma, "Studies on the removal of nickel from aqueous solutions using modified riverbed sand," Environmental Science and Pollution Research, vol. 20, no. 1, pp. 558-567, 2013.

[13] N. H. Shaidan, U. Eldemerdash, and S. Awad, "Removal of $\mathrm{Ni}(\mathrm{II})$ ions from aqueous solutions using fixed-bed ion exchange column technique," Journal of the Taiwan Institute of Chemical Engineers, vol. 43, no. 1, pp. 40-45, 2012.

[14] N. A. Khan, Z. Hasan, and S. H. Jhung, "Adsorptive removal of hazardous materials using metal-organic frameworks (MOFs): a review," Journal of Hazardous Materials, vol. 244-245, pp. 444456, 2013.

[15] K. K. Krishnani, X. Meng, and V. M. Boddu, "Fixation of heavy metals onto lignocellulosic sorbent prepared from paddy straw," Water Environment Research, vol. 80, no. 11, pp. 2165-2174, 2008.

[16] K. K. Krishnani, X. Meng, C. Christodoulatos, and V. M. Boddu, "Biosorption mechanism of nine different heavy metals onto biomatrix from rice husk," Journal of Hazardous Materials, vol. 153, no. 3, pp. 1222-1234, 2008.

[17] K. Anoop Krishnan, K. G. Sreejalekshmi, and R. S. Baiju, "Nickel(II) adsorption onto biomass based activated carbon obtained from sugarcane bagasse pith," Bioresource Technology, vol. 102, no. 22, pp. 10239-10247, 2011.

[18] L. Huang, Y. Sun, T. Yang, and L. Li, "Adsorption behavior of $\mathrm{Ni}$ (II) on lotus stalks derived active carbon by phosphoric acid activation," Desalination, vol. 268, no. 1-3, pp. 12-19, 2011.

[19] S. K. Lagergren, "Zur theorie der sogenannten adsorption gelöster stoffe," Kungliga Svenska Vetenskapsakademiens Handlingar, vol. 24, no. 4, pp. 1-39, 1898.

[20] Y. S. Ho and G. McKay, "The kinetics of sorption of divalent metal ions onto sphagnum moss peat," Water Research, vol. 34, no. 3, pp. 735-742, 2000.

[21] P. Fatehi, J. Ryan, and Y. Ni, "Adsorption of lignocelluloses of model pre-hydrolysis liquor on activated carbon," Bioresource Technology, vol. 131, pp. 308-314, 2013.

[22] G. McKay, Y. S. Ho, and J. C. Y. Ng, "Biosorption of copper from waste waters: a review," Separation and Purification Methods, vol. 28, no. 1, pp. 87-125, 1999.

[23] Y. S. Ho and G. McKay, "Sorption of dye from aqueous solution by peat," Chemical Engineering Journal, vol. 70, no. 2, pp. 115124,1998

[24] Z. Reddad, C. Gerente, Y. Andres, and P. le Cloirec, "Adsorption of several metal ions onto a low-cost biosorbent: kinetic and equilibrium studies," Environmental Science and Technology, vol. 36, no. 9, pp. 2067-2073, 2002.

[25] B. Tao and A. J. Fletcher, "Metaldehyde removal from aqueous solution by adsorption and ion exchange mechanisms onto activated carbon and polymeric sorbents," Journal of Hazardous Materials, vol. 244-245, pp. 240-250, 2013.

[26] S. Shrestha, G. Son, and S. H. Lee, "Kinetic parameters and mechanism of $\mathrm{Zn}$ (II) adsorption on lignite and coconut shellbased activated carbon fiber," Journal of Hazardous, Toxic, and Radioactive Waste, 2013.

[27] Ch. Kannan, K. Muthuraja, and M. R. Devi, "Hazardous dyes removal from aqueous solution over mesoporous aluminophosphate with textural porosity by adsorption," Journal of Hazardous Materials, vol. 244-245, pp. 10-20, 2013. 

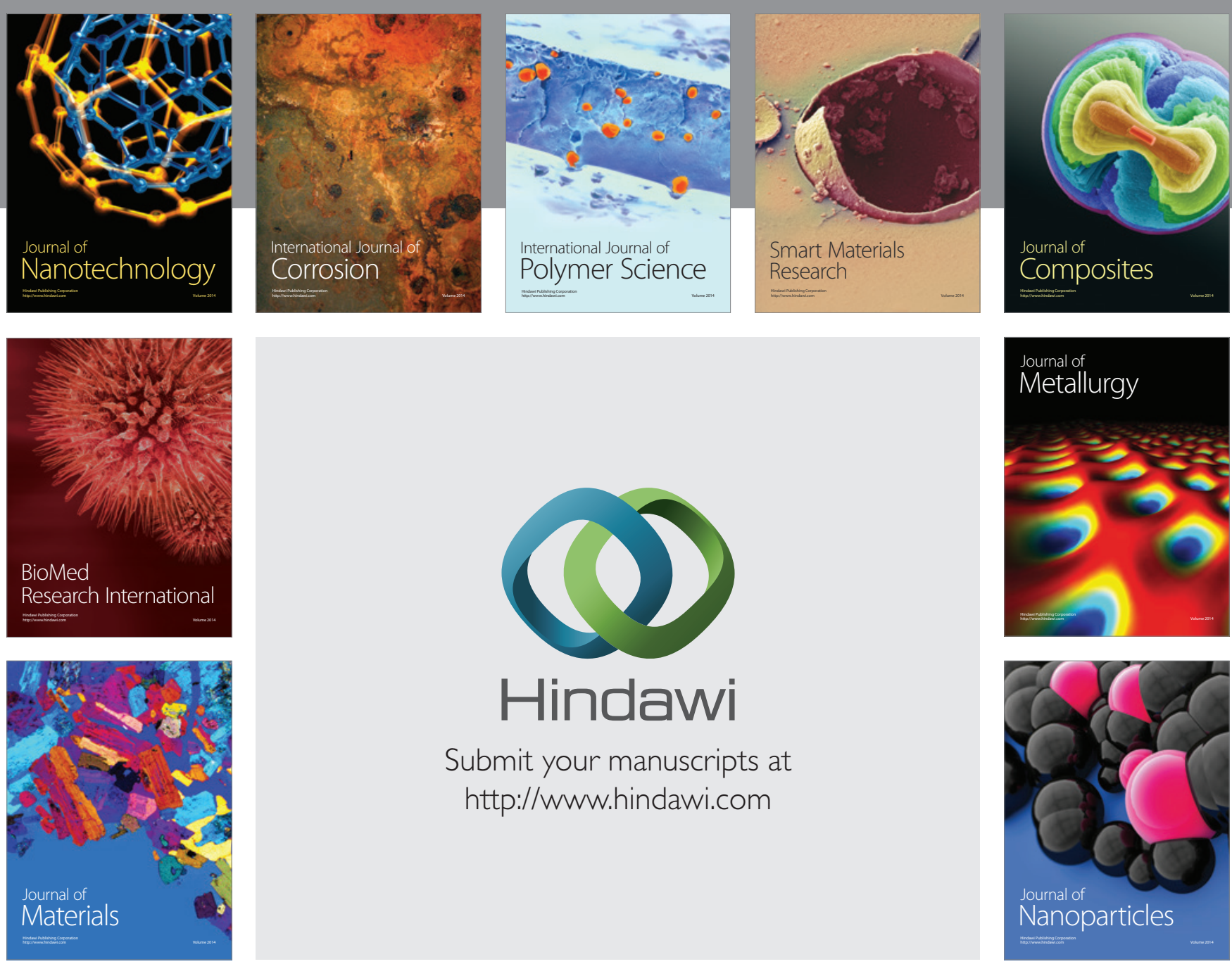

Submit your manuscripts at http://www.hindawi.com
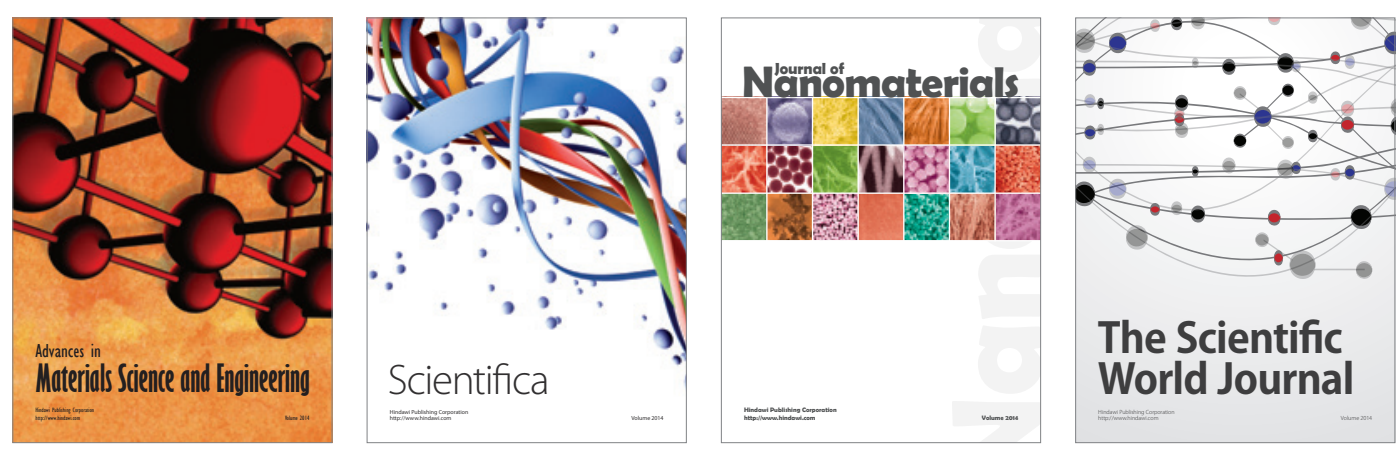

\section{The Scientific World Journal}
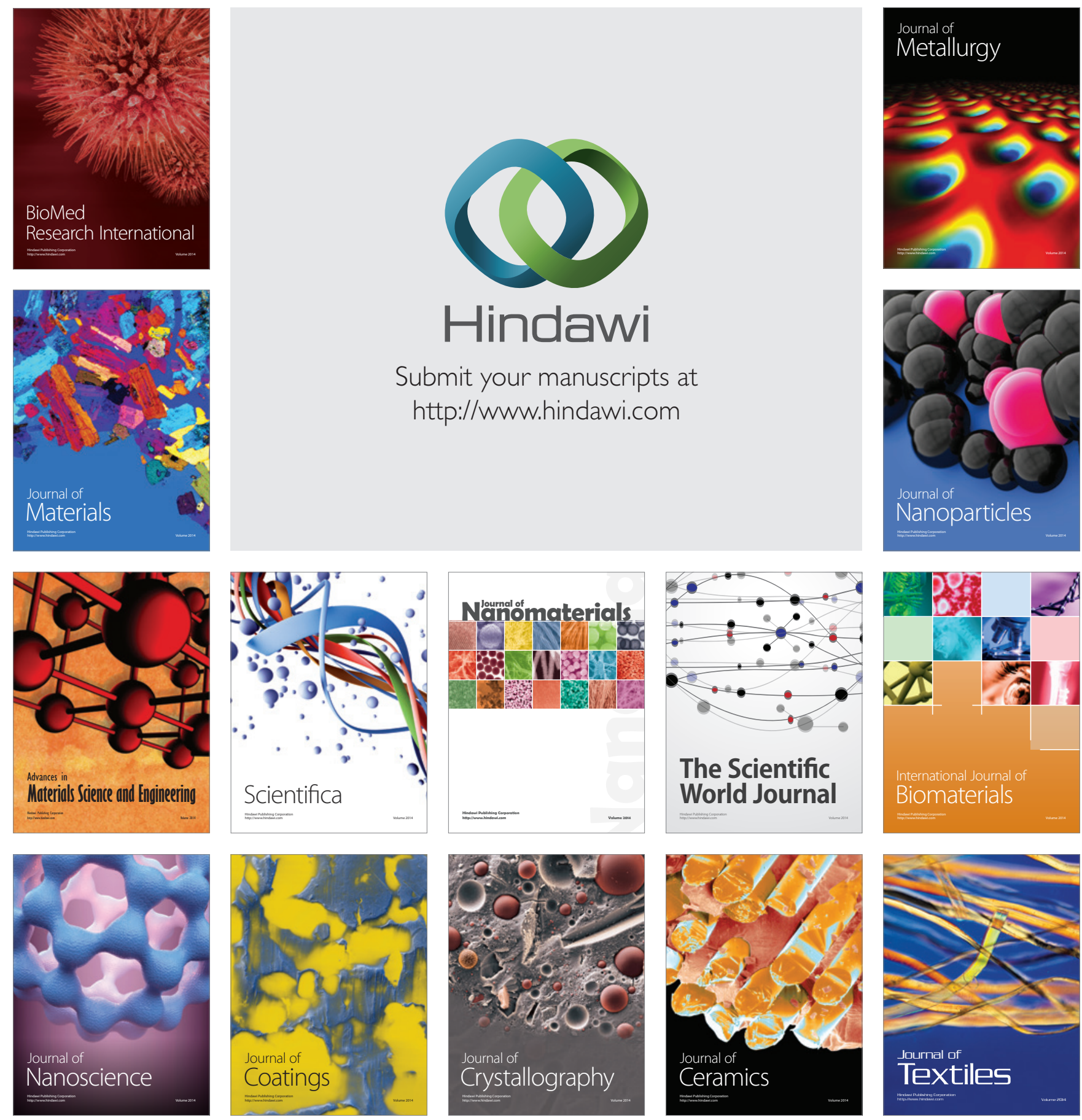